\title{
Investigating the indicators of Sustainable Architecture in Traditional Desert Houses - A Case Study of Gonabad, Iran
}

\author{
Seyedeh Maryam Mojtabavi*, Mohammad Taghi Validad \\ Department of Architecture, Asrar Institute of Higher Education, Mashhad, Iran \\ Email address: \\ Mojtabavi_m@yahoo.com (S. M. Mojtabavi), Mohamad_3853@yahoo.com (M. T. Validad)
}

To cite this article:

Seyedeh Maryam Mojtabavi, Mohammad Taghi Validad. Investigating the indicators of Sustainable Architecture in Traditional Desert Houses - A Case Study of Gonabad, Iran. International Journal of Science, Technology and Society. Special Issue: Research and Practice in Architecture and Urban Studies in Developing Countries. Vol. 3, No. 2-1, 2015, pp. 41-46. doi: 10.11648/j.ijsts.s.2015030201.19

\begin{abstract}
The traditional architecture of historic cities in Iran teaches us many lessons about the local architecture. For instance, the techniques used in designing the open spaces of desert cities are of significance considering the fact that they have made life possibility comfortable and sustainable for thousands of years despite the harsh and inconvenient conditions of these areas. In this article, we will discuss the principles of sustainable architecture and, also, assess the climatic factors in traditional houses of the desert town of Gonabad. The buildings were investigated with a comparative method using principles of sustainability. Using these experiences can be of usefulness in rebuilding residential areas. At the end, we concluded that traditional architecture, unlike modern buildings, has been very successful and we can benefit from applying their techniques to new designs because of their efficient use of climatic factors and natural resources.
\end{abstract}

Keywords: Sustainable Architecture, Traditional Buildings, Gonabad

\section{Introduction}

Human is a part of nature; therefore, if the laws of nature are sufficiently abided and men align their life with the flow of nature; it is known that comfort, convenience, economy, variety and a pleasant life will be possible in all seasons of the year. However, if we are looking for a life compatible with nature, we have to opt for what our ancestors have found and done after years of experiences; otherwise, we will miss on a huge part of the knowledge gained by human experiences so far.

A closer look into the context of living areas reveals that using renewable energy sources such as sun light, wind, etc. was a concern of man even in the past. The location and position of buildings, empty and full spaces, the building, the plan, the mass, the relation of the main elements of the plan, architectural distribution, the materials used, the dimensions of places, etc. are all defined in respect to the climate. Naturally, these things did not emerge at once, but they were learned using local experiences and the method of trial and error during a long time [1]. Traditionally, local architecture is defined as the forms which have been designed because of specific needs of people living in an area. In this kind of architecture, the distribution of the building structure leads to the maximum use of sun light and minimum airflow with the outside in winters. Also in summer, the heat penetration is minimized and air ventilation is basically enhanced [2].

In Iran, despite the technological improvements, climatic and environmental designs are not paid sufficient attention. While the architecture of buildings is to be compatible with the climate, in a way that the natural conditions contribute to the design of buildings, and the buildings are to be protected against harsh climatic conditions, and the energy needed for heating is to be minimized using natural resources [3].

\section{Problem Definition}

This research aims to study the role of open spaces in the local architecture. More specifically, we are going to investigate the role of centrality of open spaces, such as a central yard, in making the architecture consistent with sustainability principles. Therefore, in this research, open spaces, especially central yards, are assessed as a fundamental element in local sustainable architecture. The current architecture of Iran has faced different challenges because of ignoring the importance of open spaces. Open spaces, such as 
yards, squares and alleys, which were determining and pivotal factors in Iranian local architecture, have faded away because of uninformed and non-conscious imitation of what goes on in western countries.

Here, it is worth mentioning that the aim of this research and other related studies is not to conserve and repeat what we had in the past, but to use the experiences and patterns and come up with new concepts. The method employed in this research is historically descriptive accompanied by qualitative studies. The body of the research is the traditional architecture of desert and Gonabad with its hot and dry climate. The procedure done for sampling was purposeful, and the methods of collecting the data were using written sources, documents, maps and direct observations. The data were analyzed using content analysis procedures. In this research, we have reviewed the principles of sustainable architecture at first and, then used comparative methods. The principles were compared to those of buildings with central yards which were selected in the sampling procedure.

\section{Sustainable Architecture}

Sustainable architecture is defined as the kind which includes the environmental and climatic considerations and their compatibility with ecological environment so that it can be designed by using natural resources in the most efficient way possible. In sustainable architecture, it is tried to minimize the negative effects of buildings on the environment. To do so, building artificial spaces should be consistent with the available natural resources; furthermore, it is to economize on the use of non-renewable energy sources and save it for the posterity. Considering the definition of sustainable architecture, the traditional architecture of Iran in hot and dry climate is regarded as an ideal model of climatic designs [4].

In this study, the principles of sustainable architecture are reviewed from the view point of Brenda and Robert Vale which are as follows:

1. Energy saving: the building design should be aimed at minimizing the use of fossil energies

2. Consistency with the climate: the building is to be consistent with the climate and energy sources available in the place

3. Reduction in using the new material resources: the building is to be designed in way that the use of new equipment and energy sources is minimized, and the building material can be used as a new source at the end of its life.

4. The fulfillment of the needs of the residents: meeting physical and spiritual needs of the residents is of great importance (human oriented designs)

5. Compatibility with the environment: the building is to be made with amenity with the environment so that can be compatible with its surroundings

6. Generality: all the principles of sustainable architecture should be embodied in a complete process to make a healthy environment [5].

\section{Case Study: The Town of Gonabad, Iran}

Gonabad is one of the oldest towns in Iran, whose history goes back to several thousand years ago. It is located in a desert area on desert edge [6]. The latitude and longitude of Gonabad, Khorasan Razavi, Iran is $34^{\circ} 21^{\prime} \mathrm{N} / 58^{\circ} 41^{\prime} \mathrm{E}$, and it is on skirt the Siah Kouh Mountains within 35 kilometers from Kale-Shour [7]. Because of its distance from seas, and also the absence of moist air, and presence of burning winds Gonabad is among dried towns of Iran. An important factor in determining the climatic conditions of Gonabad is the existence of mountains in eastern, southern and east southern areas. Also, the Salt Desert in the north and west of the town which is accompanied by eastern winds filled with sand and dust is of significance in the climate of the town [8]. In Gonabad, due to its arid climate and the height difference from the sea level-which is more than 1500 metersthe difference between the temperature at nights and in days is rather high [7]. Architectural considerations have been finely taken into account as for the heating and cooling system of the buildings in different temperature.

\section{The Role of Central Yards in the Emergence of a Sustainable Local Architecture}

In local architecture of Iran, the outdoor and indoor spaces of a house are mostly joined,which forms a new architutral element. Open spaces have a pivotal role in this architecture and has given the local designs its own identity. Considering the principles mentioned as for sustainable architecture, we will discuss the role of central yards in the following areas.

\subsection{Central Yards and Energy Saving}

Brick walls, because of their limitted compressive strength, are wide and bulky; thus, at least four environmetal pheomena actually occur in these walls which are as follows:

Wide brick walls, due to their high heat capacity, function as heat storages. Bricks, because of their low heat transfer coefficient, are good insulators for buildingsbecause of their undelying context and the surface color, the absorption of sun radiations is limitted, while the distribution of reflcetions is highbricks, because of their high heat capacity, do absorb energy during the days in summer, but, because of a low heat transfer coefficient, the delay in heat transfer occurs very efficiently. Also, nutral structures are easily recycled or absorbed in nature because of the absence of chemical or metal elements in their structure [9].

Yards, by forming a micro climate which is fairly cold and wet, close to the building, contribute to the cooling system of the building. Architects did arrange the rooms around the yard, so the rooms and the basements get the required light from the yard (picture 1). Sun and wind shades are formed in the yards and the walls of rooms by planning ponds, growing 
trees ,especially fruit trees, plants and flowers. These have helped to reduce the infilteration of the hot summer air and sun light into the rooms, and prevent heat transfer through the floor and the walls [10].

The compact nature of buildings, which are sometimes attached to eachother from all four sides, is the other factor contributing to saving the enegy and heat of the buildings. (Picture 2). Another element which helps the process of energy saving is the planned ratio of indoor spaces to open spaces. As for the buildings which are studied in this paper, the ratio of filled places to that of the empty ones was 2.5 or somethimes even more, close to 3.5. some of the instances are listed in the table 1.

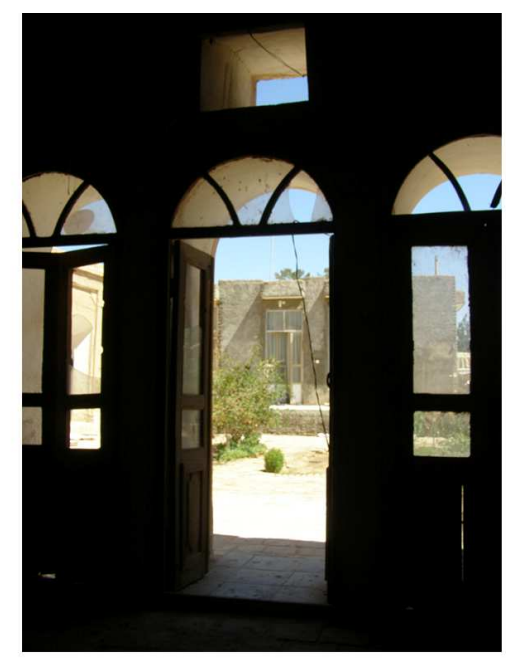

Picture 1. The skylight through central yards, the house of Khaje Beidokhti, Gonabad town

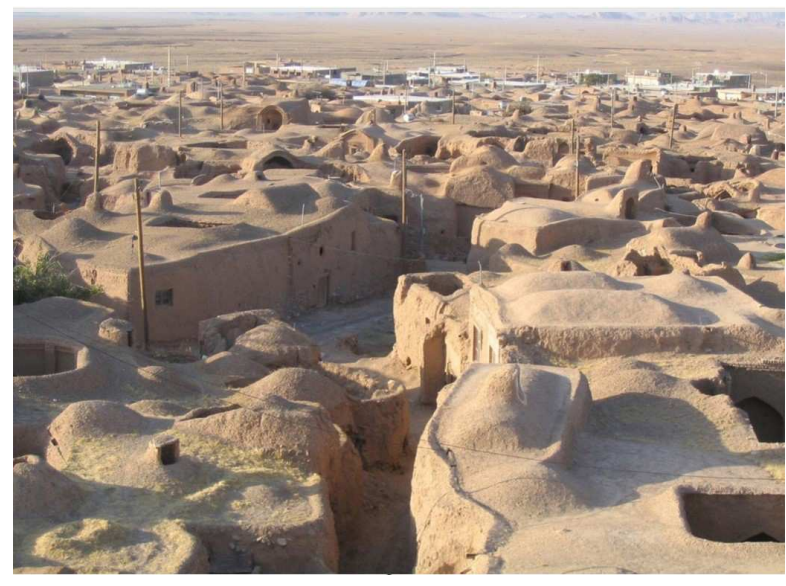

Picture 2. The compact context of Riyab village, Gonabad town

Despite the harsh conditions, local architecture in desert areas has paved the way for comfortable and sustainable accomodation for thousands of years.

\subsection{Central Yards and Climatic Considerations}

Introverted houses in hot and dry climates are like paradises in deserts. Introverted places are closed like warm arms, and is fronted to inside the house from each side. In the middle east, introverted buildings are an ideal response to tge driedness of the weather, flow of sands and the scorching sun [11].

In the yards of local houses in deserts, all comprising elemnts contribute to the liviblity of the place by establishing a micro climate. These elements act quite smartly against cold, heat, moist and wind . they function as a natural oasis which is provided for the light, water, wind and plants of the area. Wooded indoor yards, with the help of a pond and some plants are the best choice for maintanig and making the required wetness in a desert area. Therefore, rooms which open to these yards are protected from harsh winds and sand storms. The Design of filled and empty spaces such as yards with high walls and shades, indoor spaces of porches, rooms in different directions, corner winward rooms ,ponds, basements and roofs are all of signigicance during different times of the days and years; this allows people to choose and adapt their living environment with climatic changes and conditions [12].

Table 1. The ratio of the filled and empty space in traditional desert houses of Gonabad.

The ratio of the area of the Filled and empty space Building
filled and the empty space

\subsection{Central Yards and Materials}

In desert areas, soil is the most abundant element, which is cleverly made into bricks by local residents and it is known to be one of the main materials of building.

Bricks are produced with the minimum change in the environment, furthermore, they are also among the most economical materials. Since, in traditional methods, transportation of heavy materials was done by people or animals with no mechanical help, the soil beneathe the building itself was extracted to supply the required materials; thus, there was no waste in the extraction site. The required water was provided by subterraneans beneathe the ground, which required utmost one level of digging. That is, a high proportion of the required materials was produced in the site of building with no help of non-local equipment or 
materials. The extraction of materials from nature, deforming the environment, transforming the nature of the materials in factories and their transportation waste a lot of energy and produce so much pollution. This is one of the most important factors in sustainable architecture in which these steps are skipped [13].

Central yards which are equal to the structure of plateaus are highly sustainable due to some interwoven features such as heat, being acoustic, simplicity of the technology, no pollution in the production, without any energy consumption in the production, not need to transportation, not changing the nature, not being chemical, not shielding against cosmic spheres and its recycability as well as absorbility in nature [13]. (Picture3)

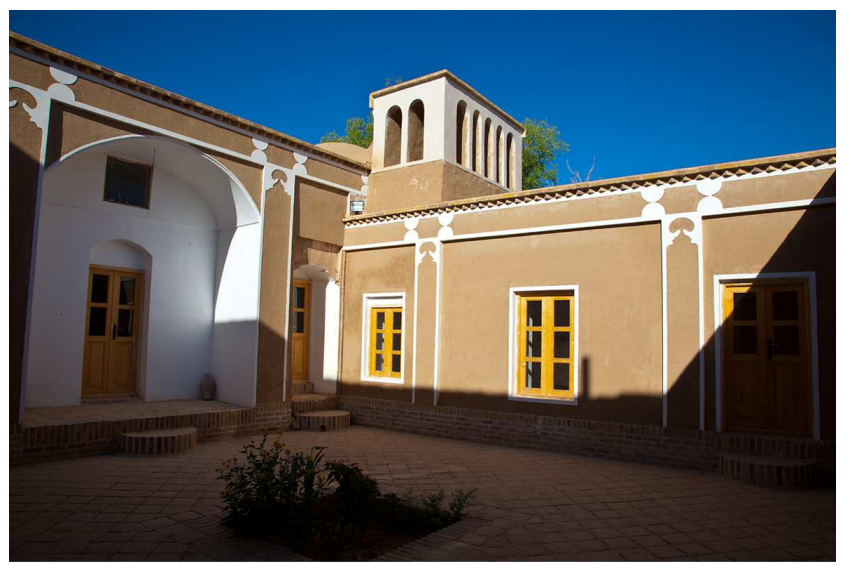

Picture 3. Employing bricks and its facet, house of Bohlul, Gonabad

\subsection{Central Yards and Meeting Residents' Needs (Respecting the Inhabitants)}

Traditional houses constructed in the desert in Iran supply a variety of people's needs thanks to their central open spaces.

Some features of these houses are as follows:

- Having privacy

- Preventing counter- overlooking of buildings

- Making houses comfortable for people and compatible with the nature

- Separating the indoor and outdoor spaces by using proper joints such as corridors and yards

- Providing all houses with natural outdoor spaces and yards for semi-open spaces such a porches for different seasons of the year

- Providing places in private spaces for establishing free relationship with nature using naturual elemnts such as water, animals and plants

- Exploiting the natural endowments such as sun light, cold and heat in the most efficient way

In Iranian traditional houses not only are, low level needs such as physiological ones addressed, but needs such as safety, love and belonging, self-esteem, aesthetics, and self actualization are sought to be met. Therefore, these buildings are human-oriented, which aim to provide meaningful participation of people, that is an importan factor of sustainable architecture. With the help of the micro environemtn of yards, people's contact with nature has become possible, which is known to be one of the basic rights of human. The arrangement of the outdoor and indoor spaces has integrated the beauty of nature with people's lives (picture 4).

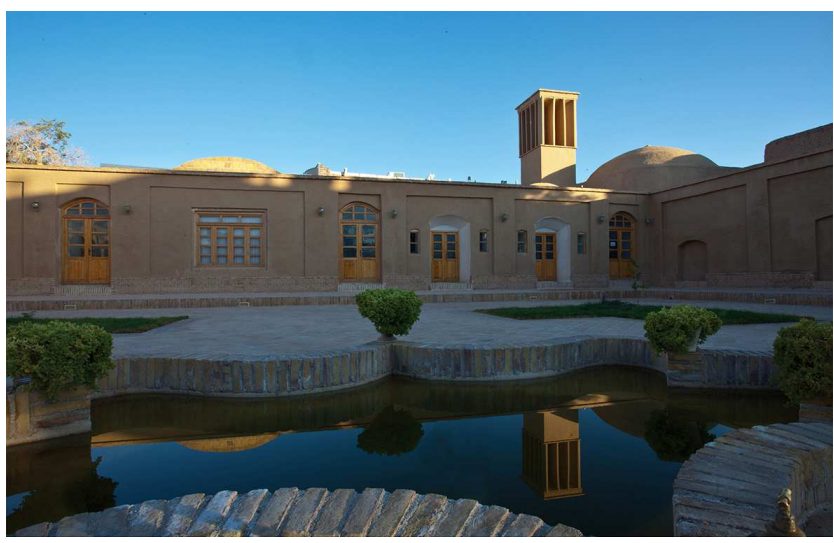

Picture 4. A central yard, connecting people with nature, Shariat's house, Gonabad

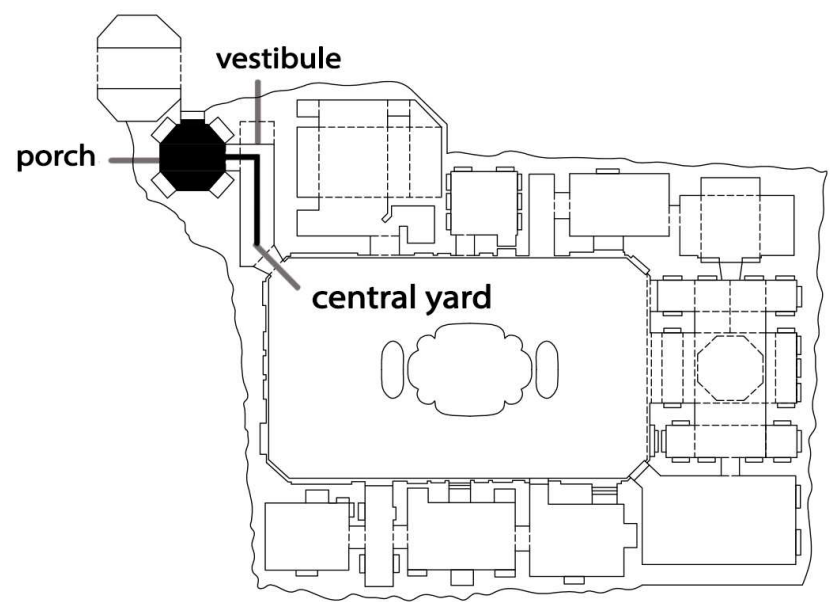

Picture 5. A plan of ways into a house, Alipur's house, Gonabad

These yards not only supply physical needs but also provide spiritual lives of inhabitants [14].

Using indoor yards, and the arrangement of indoor and outdoor spaces, houses are made turned to private places. People are allowed to enter the house through different filters such as vestibules, porches and hallways which give the residents a sense of respect and security [15]. Generally, vestibules are designed to prevent the effects of bad weather, and also obstacle the view of inside from outside [16]. (Picture 5)

\subsection{Central Yards and Its Consistancy with the Construction Site (Land Orientation)}

Site, the context of the design, is defined as the place in which the architecture occurs; it includes both content and form. Paying sufficient attention to the physical, regional, historic, social and cultural aspects of the environment is among the most important principles of architecture [9].The golden rule of Tibbalds, which means "places matter most" indicates that the context and the land are the most important 
factors in urban designing. So, the priority is with the design which puts the local context on top, which is called localism [17]. The popular slogan that says "think globally, act locally" bears testimony to this attitude, according to which a sustainable development would be gained only and only with sufficient attention to local problems and solving them, which is thought not to be achievable without the participation cooperation of the beneficiaries and international contributions. In local architecture, the existing of mutual tendency between the context and the design has led architecture to be consistent with ecology. The context of each design can be identified under the following categories.

\subsubsection{The Cultural and Social Aspects of the Construction Site}

Local orientation designs consider environmental issues in addition to those of social and humanitarian ones. It aims to support active and productive environments which provide a high quality of life for people [18].

\subsubsection{The Historic Aspects of the Construction Site}

The internal parts of historical towns in Iran, such as Gonabad, has a special physical environment, which was formed under the influence of social and cultural factors during the previous centuries. The internal parts of towns are the result of gradual and constant processes.

\subsubsection{The Climatic Aspects of the Construction Site}

The city and its climate are two man made and natural systems which closely impact eachother. Climates, as far as human's comfort is concerned, include sun light,temperature, wetness of weather, wind blowing and the amount of rain fall. A suitable climate is different from place to place and poses some limitations on urban designing. We are to pay attention to the kind of climate beside the quality and aesthetic principles in the design of different parts of cities, such as green spaces, buildings, sidewalks, etc. Ignoring this issue would cause a lot of troubles [19]. A reason for the existing of energy and environmental crises is lack of attention to regional differences. Open-space central yards in the local architechture of Gonabad are well designed based on climatic and regional aspects of the locale.

The existing convergence of architecture and regional factors is achieved through considering the special environmental location of the city, and then using local materials and natural substances; considering the regional limitations such as slopes, topography and using proper vegetation based on the available sources and exploiting climatic regulators despite all the limitations, is an essential point [20].

\subsubsection{Physical Aspects of the Construction Site}

The architect of spaces in deserts with their centeral yards has paid special attention to the physical environment. Different factors have ben considered in the designing and building of these sites such as available resources, local materials, neighbourings, the heirarchies, the vegetation, the geometry of the site, the link with nature, regional potentials, and the possible environmental potentials. Climates have always been of concerned during the history, which has been faught with by people's experience. Hot and dry climates have caused many problems for people such as the burning sunlight and heat, the difference and fluctuations of temperature during the day.

Harsh summers, cold winters, dried and unpleasant winds, and sand storms are brought about because of the desert environment. after thousand years of experience, Human beings have come up with several solutions, specially in Iran, whose main purpose is to make the individual,and simetimes the social, lives of people more comfortable and convenient [21].

\subsection{Central Yards and Generality}

Gestalt psychology considers a percieved generality to have a reality of its own, independence of the parts and even more than its parts. That is, a phenomenon is not imaginable in isolation, and cannot be conceived by its own nature and features, but there should be a surrounding context on which the phenomenon is dependent and interacts. In local architecture of deserts, buildings are not considered in isolation, but they are a part of a bigger whole, which is the environment, the nature and the surrounding ecology. The buildings of central yards not only include all principles of sustainable architecture, but have also brought these changes into urban context to establish a sustainable city [22].

\section{Discussion and Conclusion}

Gonabad is a local and traditional residence which has, for a long time, employed regional techniques to use natural resources to provide the heating and cooling system of houses. However, in recent years, the structure of the city has undergone various changes, like all other cities and towns in Iran, because of wrong policies and the emergance of subsided fossil resources and energies. These changes have limitted the role of climate and regions in residential and commercial buildings. The traditional structure of the city shows to have employed these techniques against harsh climatic conditions very efficiently, which can be seen in the plan, size, design, construction, space distribution, spacial relations, structural systems and the used materials. Therefore, the traditional context of Gonabad, in terms of climate and architecture, can be considered sustainable, whose methods of design can be employed in new buildings. Nevertheless, the modern contexts of cities have ignored the regional factors, and gained the required energy and power through mechanical and electronical resources, as well as this, a high proportion of fossil energies is also used. As a result, the experiences of traditional architecture can be very educational. It will not only make us independent from fossil energies, but also proves more comfort and even sanitary in residential areas. So, the first step to exploit natural conditions, is to make buildings more in harmony with the environment. In addition, if these kinds of designs are combined with new technologies and materials, a great deal of energy can also be saved. 


\section{References}

[1] Coch H (1996), "Bioclimatism in vernacular architecture. Renewable and Sustainable Energy Reviews; 2(1-2): pp. $67-87$

[2] Pourderhami, "Construction consistent with the climate", Safe quarterly, $9^{\text {th }}$ year, ed. 27. 1999, pp.62-71.

[3] Building rules and regulations organization, "national building regulations: Economizing on use of energy" sect. $19^{\text {th }}$ s. Tehran: Ministry of urbanization, 2006.

[4] F. Saflaiey "Sustainability of national elements in Iranian traditional architecture" $33^{\text {rd }}$ international Conference of optimization of fuel use, 2003.

[5] Vale, B. and R. Value, (1996) Green Architecture: Design for a Sustainable Future, London: Thames \& Hudson Ltd.

[6] H. Mojtabavi, Gonabad's geographical history, ed.1 ${ }^{\text {st }}$, Mashhad, Marandiz press, 1995.

[7] M. Papaliyazdi, Gonabad's Aqueduct as a myth, ed. $1^{\text {st }}$, Khorasan Sahambi Ab co. press, 2000.

[8] Gh. Yazdi, A. Keivanlushahrestanaki, "Identification of educational needs in rural areas," Jahad sazandegi press, 1991.

[9] Z. Ahmadi, "Contextualizing the sustainable architecture" Sustainable architecture Conf., Azad university press, 2009.

[10] M. Bahadorinezhad, M. Yaghubi, "Natural cooling in traditional houses in Iran" ed.1 ${ }^{\text {st }}$, Tehran: University center press, 2006.

[11] K. Pirnia, "Stylistics in Iranian architecture' ed. $6^{\text {th }}$, Tehran: Sorush Danesh press, 2008.
[12] A. Ghafari, "The structure of form and establishment of sustainable development in urbanization and architecture" Saffe Mag, vol. 34, Spring and Summer 2002. .

[13] F. Ahmadi, "City,home,central yard" Saffe mag., vol. 41, Fall and Winter 2005.

[14] S. Eftekharzadeh, "Spacial recovery, turning a building to a home", Architectural quartly, vol. 6. Summer 2005.

[15] F. Kateb, "Architecture in Iranian houses" ministry of culure and Islanic guidance, Tehran: Print and publication co., 2005.

[16] A. Arvin, M. Niazi, "Kashan's historical houses, and their regional architecture and features" KashanShenakht quartly, vol. 3, Spring and Summer 2006.

[17] Carmona, matthew, healt, tim,Oc,taner, tiesdell,steve,2003,"public places, urban spaces, oxford, architectural press

[18] R. Taghadosi, "An investigation of design principles amd urban sustainability", architecture and urbanization students conf., Tehran: Farhangestan Honar press 2002.

[19] R. Sheikhbiglu, J. Muhammadi, "Analysis of regional elements of winding and raining based on a case study of Isfahan city" Geography and environmental planning mag., year. 21, vol. 39, 2010

[20] M. Noghsan Muhammadi, F. Dehghan, M. Montazeri, "Designing modern localist city environment: a reconciliation of development and sustainability using localist designs in streets of Yazd city" vol. 2, 2012.

[21] H. Zamarshidi, "Iranian architecture using traditional materials" vol. 10, Tehran: Zomorod press, 2008

[22] Kenyang, "Ecologic design in green architecture" (S. Zangane, Trans.) Abadi Journal, vol. 42, 2004 